\title{
Does the Prevalence of Skin Cancer Differ by Metropolitan Status for Males and Females in the United States?
}

\author{
Hannah J Bram, Megan Frauendorfer, Shawna Spencer and Jessica L Hartos*
}

Department of Physician Assistant Studies, University of North Texas Health Science Center, USA

*Corresponding author: Jessica Hartos, Department of Physician Assistant Studies, University of North Texas Health Science Center, USA Tel: 817-735-2454; Fax: 817-735-2529; E-mail: Jessica.hartos@unthsc.edu

Received date: November 13, 2017; Accepted date: December 7, 2017; published date: December 14, 2017

Citation: Bram HJ, Frauendorfer M, Spencer S, Hartos JL (2017) Does the Prevalence of Skin Cancer Differ by Metropolitan Status for Males and Females in the United States? J Prev Med Vol.2 No.3:9.

Copyright: (c) 2017 Bram HJ, et al. This is an open-access article distributed under the terms of the Creative Commons Attribution License, which permits unrestricted use, distribution and reproduction in any medium, provided the original author and source are credited.

\section{Abstract}

Purpose: Skin cancer is a major health concern in the general population, but there are conflicting findings regarding its relationship to where people live. The purpose of this study was to determine whether skin cancer differs by metropolitan status in the general population of U.S. adult males and females aged 18 and older.

Methods: This cross sectional analysis used 2015 data from the Behavioral Risk Factor Surveillance System (BRFSS) for males and females aged 18 years and older. Multiple logistic regression analysis was used to assess the relationship between skin cancer and metropolitan status separately by gender while controlling for other cancers, general health, educational level, employment status, income level, ethnicity, and age.

Results: Across states, $20 \%$ of males and $15 \%$ of females reported skin cancer and roughly $20 \%$ of both males and females lived in rural areas, $40 \%$ in suburban areas, and $40 \%$ in urban areas. After controlling for health, socioeconomic and demographic factors, skin cancer and metropolitan status were significantly related for both males and females. Skin cancer was also related to other cancers, income level, ethnicity/race, and age for both genders.

Conclusion: This study found that skin cancer significantly differed by metropolitan status with both males and females living in suburban areas reporting more cancer than those living in urban or rural areas. Limitations to this study include a broad definition of skin cancer and no lifestyle variables specific to sun exposure. It is recommended that general practitioners screen, educate, and provide referral services as necessary for both males and females, especially those who live in suburban areas, have a history of cancer, are 65 or older, and are white, non-Hispanic.

Keywords: Skin cancer; Metropolitan status; Suburban; Rural; Urban; Adults; Age Differences; Gender Differences

\section{Introduction}

Skin cancer is the most prevalent type of cancer in the United States [1], and its incidence has significantly increased by $45 \%$ since 1992 [2]. Among adolescents and young adults specifically, invasive skin cancer is the second most commonly diagnosed cancer, making up $15 \%$ of all cancer diagnoses in $15-29$ year olds $[3,4]$. Moreover, numerous studies have shown skin cancer incidence significantly increasing in older adults $[2,5,6]$. The rise in skin cancer carries a burden of morbidity and cost in the United States, with 8,000 deaths and $\$ 3.5$ billion lost in productivity each year $[5,6]$. Furthermore, while melanoma accounts for approximately $75 \%$ of all deaths from skin cancer, basal cell and squamous cell carcinomas can still lead to severe illness and disfigurement [7], placing significant stress on quality of life.

Several demographic factors have been related to an increased risk of skin cancer, but with varying results. For example, some research indicates that the incidence of melanoma was highest among high income households, counties with high education rates, and low unemployment rates [8]. Conversely, other research found that that individual from lower socioeconomic status groups had the largest increase in melanoma prevalence in the United States [2]. In addition, poverty status has also been cited as having an influence on skin cancer incidence, as counties with low poverty rates have an increased risk of skin cancer compared to counties with high poverty rates [8]. Despite these differences, most studies conclude that the incidence of melanoma is highest among non-Hispanic whites when compared to other races and ethnicities $[2,8]$.

In addition, gender and age differences related to skin cancer vary. Many studies have shown skin cancer affects males more than females and is highly prevalent amongst the older population [2,6]. For melanoma, data from the National Program of Cancer Registries (NPCR) showed that women have a greater risk of being diagnosed with melanoma and increased incidence over time [4]. However, data from the Surveillance, Epidemiology, and End Results (SEER) program of the National Cancer Institute $(\mathrm{NCl})$ reported males to have a greater diagnosis 
incidence compared to the female incidence rate, as well as higher mortality rates in males younger than age 30 [3].

Furthermore, metropolitan status may be related to skin cancer, but research findings are conflicting. Some studies found a positive relationship between skin cancer incidence and population density, while others did not [9]. Numerous European studies have shown individuals living in urban regions have an increased incidence of skin cancer compared to individuals living in rural regions $[6,10,11]$. However, a study conducted in the United States suggested metropolitan status was not significantly related to incidence of invasive cutaneous melanoma [8]. Therefore, the purpose of this study was to determine whether skin cancer differs by metropolitan status in adults age 18 and older by gender in the general United States population when controlling for demographic factors that may be related to skin cancer.

\section{Methods}

\section{Design}

This cross-sectional analysis used data from the 2015 Behavioral Risk Factor Surveillance System (BRFSS) conducted by the Centers for Disease Control and Prevention (CDC) [12]. BRFSS conducts annual national, population-based data collection using random digit dialing for health-related behaviors, conditions, and services acquired via telephone surveys in all 50 states and the District of Columbia. This study was given exempt status by The University of North Texas Health Science Center.

Table 1: Sample characteristics separately for males and females.

\section{Sample}

The sample for this study included males and females ages 18 years and older from Florida ( $\mathrm{N}=4872$ ), North Carolina ( $\mathrm{N}=1793$ ), and Tennessee $(\mathrm{N}=3127)$ with data for metropolitan status. This study includes multiple states in order to increase sample size and strengthen the generalizability of results to the general population. These states were identified as having higher percentages of skin cancer when compared all other states within the continental United States using the BRFSS 2015 prevalence map [13].

\section{Data}

The outcome, skin cancer, was measured as ever/never diagnosed with skin cancer in the person's lifetime. The factor of interest, metropolitan status, was categorized as rural, suburban, or urban based on the defined metropolitan statistical area, which is determined by the United States Office of Management and Budgets to organize geographic regions by population density and zip code analysis [14].

The control variables included other cancers, general health, educational level, employment status, income level, ethnicity/ race, age, and gender. Other cancers was measured as ever/ never diagnosed with "any form of cancer, except skin cancer." General health was dichotomized as "good or better" versus "fair or poor."

\begin{tabular}{|c|c|c|c|c|}
\hline \multirow[b]{2}{*}{ Variable } & \multicolumn{2}{|c|}{$\begin{array}{l}\text { Male } \\
(\mathrm{N}=3729,38 \%)\end{array}$} & \multicolumn{2}{|c|}{$\begin{array}{l}\text { Female } \\
(\mathrm{N}=6063,62 \%)\end{array}$} \\
\hline & $\mathrm{N}$ & $\%$ & $\mathrm{~N}$ & $\%$ \\
\hline \multicolumn{5}{|l|}{ Skin Cancer } \\
\hline Ever diagnosed & 737 & 20 & 889 & 15 \\
\hline Never diagnosed & 2992 & 80 & 5174 & 85 \\
\hline Total & 3729 & 100 & 6063 & 100 \\
\hline \multicolumn{5}{|c|}{ Metropolitan Status } \\
\hline Suburban & 1501 & 40 & 2416 & 40 \\
\hline Urban & 1544 & 41 & 2569 & 42 \\
\hline Rural & 684 & 18 & 1078 & 18 \\
\hline Total & 3729 & 100 & 6063 & 100 \\
\hline \multicolumn{5}{|l|}{ Other Cancer } \\
\hline Ever & 471 & 13 & 822 & 14 \\
\hline Never & 3258 & 87 & 5241 & 86 \\
\hline Total & 3729 & 100 & 6063 & 100 \\
\hline General Health & & & & \\
\hline
\end{tabular}




\begin{tabular}{|c|c|c|c|c|}
\hline Good or better & 2901 & 78 & 4662 & 77 \\
\hline Less than good & 828 & 22 & 1401 & 23 \\
\hline Total & 3729 & 100 & 6063 & 100 \\
\hline \multicolumn{5}{|l|}{ Educational Level } \\
\hline Graduated & 1564 & 42 & 2005 & 33 \\
\hline Did not graduate & 2165 & 58 & 4058 & 67 \\
\hline Total & 3729 & 100 & 6063 & 100 \\
\hline \multicolumn{5}{|l|}{ Employment Status } \\
\hline Employed & 1462 & 39 & 1965 & 32 \\
\hline Not employed & 2267 & 61 & 4098 & 68 \\
\hline Total & 3729 & 100 & 6063 & 100 \\
\hline \multicolumn{5}{|l|}{ Income Level } \\
\hline$\$ 0$ to less than $\$ 25,000$ & 894 & 24 & 2187 & 36 \\
\hline$\$ 25,000$ to less than $\$ 50,000$ & 984 & 26 & 1654 & 27 \\
\hline$\$ 50,000$ or more & 1851 & 50 & 2222 & 37 \\
\hline Total & 3729 & 100 & 6063 & 100 \\
\hline \multicolumn{5}{|l|}{ Ethnicity/Race } \\
\hline White, non-Hispanic & 3026 & 81 & 4727 & 78 \\
\hline Other & 703 & 19 & 1336 & 22 \\
\hline Total & 3729 & 100 & 6063 & 100 \\
\hline \multicolumn{5}{|l|}{ Age } \\
\hline 65 or older & 1896 & 51 & 2966 & 49 \\
\hline Less than 65 & 1833 & 49 & 3097 & 51 \\
\hline Total & 3729 & 100 & 6063 & 100 \\
\hline
\end{tabular}

Educational level was measured by ever/never graduated from college or technical school. Employment status was dichotomized as "employed" or "not employed" (which includes retired) at the time of survey completion.

Income level was measured as an annual income "\$0 to less than $\$ 25,000$," “\$25,000 to less than $\$ 50,000$," and “\$50,000 or more." Because there were low frequencies for races other than White, race/ethnicity was dichotomized as "white, nonHispanic" versus "other." Age was dichotomized "65 years or older" versus "Less than 65 years of age."

\section{Analysis}

Frequency distributions were used to describe the sample and determine any issues with distributions of variables. Multiple logistic regression analysis was used to assess the relationship between skin cancer and metropolitan status separately by gender while controlling for health and demographic factors.

There was no missing data for any variable. The data responses for sample characteristics are listed in Table 1 and the results of multivariable analysis are recorded in Table 2.

All analyses were conducted in $\mathrm{R}$, a free statistical analysis shareware program created by the CDC that is now publicly available ( $R$ version 3.3.3, Copyright 2017, The R Foundation for Statistical Computing).

Table 2: Results of multiple logistic regressions separately for males and females. 


\begin{tabular}{|c|c|c|c|c|c|c|}
\hline \multirow[t]{3}{*}{ Skin Cancer (Ever vs. never diagnosed) } & \multicolumn{3}{|l|}{ Males } & \multicolumn{3}{|l|}{ Females } \\
\hline & \multirow{2}{*}{ AOR } & \multicolumn{2}{|c|}{$95 \% \mathrm{Cl}$} & \multirow{2}{*}{$\begin{array}{l}\text { AOR } \\
\text { Low }\end{array}$} & \multicolumn{2}{|c|}{$95 \% \mathrm{Cl}$} \\
\hline & & Low & High & & High & \\
\hline Metropolitan Status & - & - & - & - & - & - \\
\hline Suburban & Ref & - & - & Ref & - & - \\
\hline Urban & 0.77 & 0.63 & 0.93 & 0.84 & 0.71 & 0.99 \\
\hline Rural & 0.73 & 0.57 & 0.94 & 0.74 & 0.59 & 0.92 \\
\hline Other Cancer & - & - & - & - & - & - \\
\hline Ever & 2.02 & 1.61 & 2.52 & 1.67 & 1.38 & 2.02 \\
\hline General Health & - & - & - & - & - & - \\
\hline Good or better & 0.85 & 0.68 & 1.06 & 0.87 & 0.72 & 1.05 \\
\hline Educational Level & - & - & - & - & - & - \\
\hline Graduated & 0.99 & 0.82 & 1.21 & 1.2 & 1.01 & 1.43 \\
\hline Employment Status & - & - & - & - & - & - \\
\hline Employed & 0.69 & 0.54 & 0.88 & 0.81 & 0.66 & 1 \\
\hline Income Level & - & - & - & - & - & - \\
\hline$\$ 0$ to less than $\$ 25,000$ & Ref & - & - & Ref & - & - \\
\hline$\$ 25,000$ to less than $\$ 50,000$ & 1.13 & 0.87 & 1.47 & 1.17 & 0.96 & 1.43 \\
\hline$\$ 50,000$ or more & 1.32 & 1.02 & 1.71 & 1.3 & 1.06 & 1.6 \\
\hline Ethnicity/Race & - & - & - & - & - & - \\
\hline White, non-Hispanic & 5.64 & 3.79 & 8.4 & 8.76 & 5.88 & 13.1 \\
\hline Age & - & - & - & - & - & - \\
\hline 65 or older & 3.57 & 2.83 & 4.51 & 2.69 & 2.24 & 3.23 \\
\hline
\end{tabular}

\section{Results}

\section{Descriptive}

Overall, this combined sample consisted of mostly white, nonHispanic participants who have never been diagnosed with skin cancer, and report good or better health. As shown in Table 1, there were low percentages of participants who reported ever being diagnosed with skin cancer (20\% for males and $15 \%$ for females) across states. For both males and females, about $20 \%$ reported living in rural areas, while about $40 \%$ reported living in suburban areas and $40 \%$ in urban areas. Compared to females, males had higher education and income levels; however, similar amounts of males and females were employed (about one-third) and were age 65 or older (about one-half). Over $75 \%$ of males and females reported good or better health and over $85 \%$ reported having no other cancer diagnosis.

\section{Adjusted}

The results of multiple logistic regression indicated that after controlling for health and demographic variables, skin cancer differed by metropolitan status for both males and females. Compared to those living in suburban areas, skin cancer was 1.37 times less likely to be reported by males and 1.35 times less likely to be reported by females living in rural areas; and 1.30 times less likely to be reported by males and 1.19 times less likely to be reported by females living in urban areas. In addition, skin cancer was related to other cancers, income level, ethnicity/ race, and age for both males and females. Skin cancer was about 2 times more likely in males and females ever diagnosed with other cancers; about 1.5 times more likely in those of higher income levels ( $\$ 50,000$ or more); about 6 to 9 times more likely in males and females who reported white race; and about 3 to 4 times more likely in males and females aged 65 or older.

\section{Discussion}

The purpose of this study was to determine whether skin cancer differed by metropolitan status in a general population of U.S. male and female adults 18 years and older when controlling for other demographic factors that may be related to skin cancer. In this study, $15-20 \%$ females and males reported skin cancer and most lived in suburban (about 40\%) and urban 
(about 40\%) areas. The results of adjusted analysis indicated that skin cancer was significantly related to metropolitan status. Our findings conflict with other studies that did not find a significant relationship between any defined metropolitan status and skin cancer $[6,8,9,11]$ and those that found a significant relationship between skin cancer and living in rural versus nonrural areas [9]. The results of this study found a significant relationship between skin cancer and suburban versus rural areas as well as suburban versus urban areas.

Compared to those living in suburban areas, males and females in rural areas and males in urban areas were about 35\% less likely to report skin cancer, and females living in urban areas were about $20 \%$ less likely to report skin cancer. The relationship between skin cancer and suburban status may be related to socioeconomic or lifestyle factors related to expendable income and increased recreational UV exposure [6], For example, those who live in rural areas or work outdoors may get more sun exposure, but may be more likely to cover exposed areas (e.g., those working on farms and in construction wear hats, long sleeve shirts, and pants to work), whereas those at recreational activities at outdoor social locations such as swimming pools, backyard activities, community parks, etc., may be less covered up (e.g., swimsuits, tank tops, and shorts) and get more direct exposure without added protection. In addition, those with disposable income may be more likely to use tanning beds, which pose greater risk for skin cancer [15]. Indeed, higher incomes levels for both males and females were related to about a $30 \%$ increased risk for skin cancer. Furthermore, specific demographic characteristics such as race and age were found to be significantly related to skin cancer in this study. The relationship between white, non-Hispanic ethnicity and skin cancer and between age 65 and older was consistent with multiple previous studies $[2,5,6,8]$.

Using BRFFS data allowed us to assess variable relations in population-based samples, and the large number of respondents allowed us to analyze data by gender. However, the measurement of skin cancer was limited to "ever diagnosed with skin cancer," which does not differentiate between types of skin malignancies nor location, severity, or grading of the cancer. Investigation into specific skin cancer types such as melanoma versus carcinoma would more clearly define and direct skin cancer diagnosis in the clinical setting. Another limitation of this study includes the lack of additional lifestyle variables such as sun exposure, occupation, or preventative care measures that are related to skin cancer [6], which could lead to more applicable preventative care for at risk populations. Expanded research within the field could also include assessment of narrowed target population ages, influence of access to healthcare, and availability of potential treatment options [8] to further refine treatment. Furthermore, the unknown duration of residency of participants in their metropolitan category in this study may reduce the generalizability of the results to patient populations.

\section{Conclusion}

The results of this population-based study may be generalizable to patients aged 18 years and older in a primary care setting. Different results may be found in dermatology or oncology specialty clinics where skin cancer may be more prevalent. In primary care settings, providers should be award of the low prevalence of skin cancer amongst patients 18 years and older as well as the increased risk for skin cancer in those living in suburban areas, having been diagnosed with any other form of cancer, having white, non-Hispanic race/ethnicity, and being 65 years and older. Providers should have elevated concern for patients in these groups, and continue to provide annual skin screening as well as screening for specific skin-related concerns, and provide education, screening, and referral to dermatology or oncology as appropriate.

\section{Conflict of Interest}

None of the authors have any conflicts of interest

\section{Sources of Support}

None

\section{References}

1. (2016) Centers for Disease Control and Prevention (CDC). Skin Cancer Statistics.

2. Linos E, Swetter SM, Cockburn MG, Colditz GA, Clarke CA (2009) Increasing burden of melanoma in the United States. J Investig Dermatol 129: 1666-1674.

3. Bleyer A, Viny A, Barr R (2006) Cancer in 15-to 29-year-olds by primary site. Oncologist 11: 590-601.

4. Weir HK, Marrett LD, Cokkinides V, Barnholtz-Sloan J, Patel P, et al. (2011) Melanoma in adolescents and young adults (ages 15-39 years): United States, 1999-2006. J Am Acad Dermatol 65: S38S49.

5. Centers for Disease Control and Prevention (CDC). Melanoma Surveillance in the United States.

6. Deady S, Sharp L, Comber H (2014) Increasing skin cancer incidence in young affluent urban populations: A challenge for prevention. Br J Dermatol 171: 324-331.

7. (2002) Centers for Disease Control and Prevention (CDC). Skin Cancer: Preventing America's Most Common Cancer Fact Sheet.

8. Singh SD, Ajani UA, Johnson CJ, Roland KB, Eide M, et al. (2011) Association of cutaneous melanoma incidence with area-based socioeconomic indicators - United States, 2004-2006. J Am Acad Dermatol 65: S58-S68.

9. Monroe AC, Ricketts TC, Savitz LA (1992) Cancer in rural versus urban populations: A review. J Rural Health 8: 212-220.

10. Carsin AE, Sharp L, Comber H (2011) Geographical, urban/rural and socioeconomic variations in nonmelanoma skin cancer incidence: A population-based study in Ireland. Br J Dermatol 164: 822-829.

11. Sharp L, Donnelly D, Hegarty A, Carsin AE, Deady S, et al. (2014) Risk of several cancers is higher in urban areas after adjusting for socioeconomic status. Results from a two-country populationbased study of 18 common cancers. J Urban Health 91: 510-525.

12. Centers for Disease Control and Prevention (CDC) (2017) About BRFSS. 
13. Centers for Disease Control and Prevention (CDC) (2017) BRFFS Prevalence \& Trends Data.

14. Centers for Disease Control and Prevention (CDC) (2017) SMART: BRFFS City and County Data and Documentation.
15. Levine JA, Sorace M, Spencer J, Siegel DM (2005) The indoor UV tanning industry: A review of skin cancer risk, health benefit claims, and regulation. J Am Acad Dermatol 53: 1038- 1044. 